\section{Building Exhibition at Olympia, London}

THREE HUNDRED AND FIFTY firms and associations have already booked space in the twentieth biennial Building Exhibition which is to be held at Olympia, London, on September 16-30. This number of exhibitors is in excess of the number which exhibited on the last occasion in 1934, and an increase of about 10 per cent in the total number may be expected. The Department of Scientific and Industrial Research is again to have a large exhibit, and this will cover not only the work of the Building Research Station, but also that of the Forest Products Research Laboratory, Princes Risborough, and the National Physical Laboratory, Teddington. The Building Research Station exhibit will deal with plastering materials; common types of failure caused by using unsuitable material or by faulty construction; concretes, with special emphasis on light-weight concrete; further work on the driving of concrete piles; the measurement of strain on masonry structures; and the weathering of building stone. The work of the Forest Products Research Laboratory illustrated in the Exhibition will deal with the correct moisture content of timbers for various purposes; wood-working, with special reference to new and difficult timbers; and wood preservation and protection against the death-watch and other beetles. The National Physical Laboratory's exhibit will deal chiefly with building acoustical problems, models being shown of typical quiet and noisy rooms. Short-length films are to be shown by the Department on its stands.

\section{Observations on Comets}

A CONSIDERABLE number of observations of Peltier's comet are now available, and the Rev. Dr. M. Davidson has computed a new orbit, using observations from May 16 to July 15, the latter being made by Dr. W. H. Steavenson and independently by Mr. Will Hay. The period appears to be about 1500 years, but observations from the southern hemisphere, in which the comet can be followed up to October, will enable computers to obtain a more accurate period. The comet is rapidly moving sonth, and will not be visible in these latitudes after August 6 . A comet of sixth magnitude was discovered by Kaho on July 17, and a number of observations have since been made at various observatories and also by members of the British Astronomical Association. The orbit given below was computed by Whipple and Cunningham, but as the observations used were very rough, the orbit is only approximate. Dr. Crommelin, having received more accurate observa. tions, is now engaged in computing a general orbit. The comet is receding from the earth and sun and is fading rapidly.

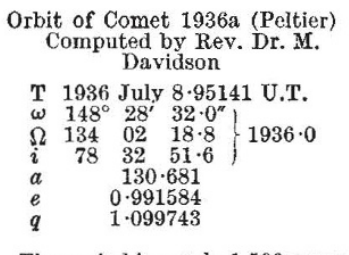

Orbit of Comet Kaho Computed by Messrs. Whipple and Cunningham

T 1936 July $13 \cdot 700$ U.T.

$\begin{array}{lll}\omega & 40^{\circ} & \left.56^{\prime}\right)\end{array}$

$\left.\begin{array}{lll}\omega & 40 & 56 \\ & 262 & 02\end{array}\right\} 1936 \cdot 0$ $\begin{array}{lll}i & 123 & 08 \\ q & 0.5220\end{array}$

\section{Announcements}

Robert Esnault-Pelterie has been elected a member of the Division of the Applications of Science to Industry of the Paris Academy of Sciences in succession to the late Jean Rey.

AT the quarterly meeting of the Royal College of Physicians held on July 30, the Weber-Parkes Medal and Prize were awarded to Sir St. Clair Thomson for his work on tuberculosis of the larynx, and the Moxon Gold Medal to Prof. Edward Mellanby for his work on the problems of nutrition. The Harveian Oration will be delivered by Sir Walter LangdonBrown on October 19, at 4 p.m. Dr. Arthur Hurst has been appointed Harveian Orator for 1937 and Dr. E. A. Cockayne Bradshaw Lecturer for 1937.

The Royal Academy of Belgium has made the following awards: Lefebvre Prize to MM. Wattiez and Sternon; Laurent Prize to M. R. Bouillenne; Van Beneden Prize to M. J. Brachet and grants from the De Potter Fund to M. A. Gardedieu, M. Capron, M. van den Bruel and M. Florkin.

Dr. GotTlieb Haberlandt, emeritus professor of botany in the University of Berlin, has been made an honorary member of the Academy of Sciences of Vienna.

THE Austrian Society for Roentgenology will hold its annual meeting at Vienna on September 4-8. Further information can be obtained from Allgemeines Krankenhaus, Zentral-Roentgen Institut, Alserstrasse 4, Wien I.

Applications are invited for the following appoint. ments, on or before the dates mentioned :

Junior assistants (physics or chemistry) in the Chemical Defence Research Department (War Department)-The Chief Superintendent, Chemical Defence Research Department, 14 Grosvenor Gardens, S.W.1 (August 12).

A lecturer in electrical engineering in Walsall Technical College-The Director of Education, Education Offices, Council House, Walsall (August 15).

An assistant lecturer and demonstrator in civil engineering in University College, Cardiff-The Registrar (August 19).

A part-time assistant lecturer in the Department of Physics and Applied Physies in the Technical College, Cardiff-The Director of Education, City Hall, Cardiff (August 24).

An assistant director of the Plant Pathological Laboratory, Harpenden-The Secretary, Ministry of Agriculture and Fisheries, 10 Whitehall Place, London, S.W.1 (August 31).

A senior assistant in the Department of Surgery of the Royal Veterinary College-The Secretary (August 31).

An assistant curator in the Royal Albert Memorial Museum, Exeter-The Town Clerk, Exeter (August 31).

A lecturer in physiology in the University of Western Ontario, London, Ontario, Canada-The Dean of the Medical School. 